\title{
Crimen y Castigo: una mirada al aspecto criminalistico
}

Hugo de Romaña Velarde"

- Abogado, Defensor Público, Caredrático de la Facultad de Derecho de la Universidad Alas Peruanas - Filial Arequipa en el área de Criminologia y Ciencia Politica. Estudios de Maestría en Derecho Penal en la Escuela de Post Grado de la Universidad Católica de Santa Maria de Arequipa. Autor de la tesis: "Estudio sobre la Pirateria Fonográfica en el Perú".

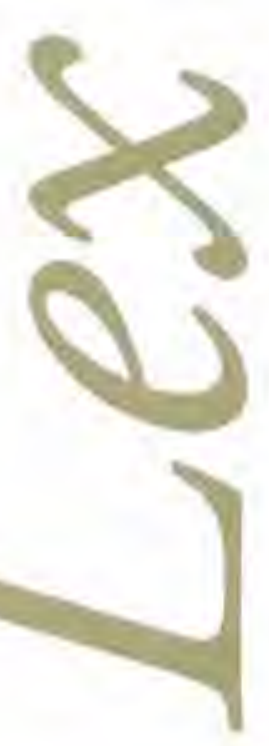





\section{Crimen y Castigo: una mirada al aspecto criminálistico}

Al Dr: Pablo Alfonso Rodriguez Regalado, quien sembró la semilla que generó el amor por esa maravillosa ciencia.

El crimen constituye uno de los aspectos más apasionantes de la historia universal. Desde la historia bíblica que convierte a Caín en asesino de su propio hermano, hasta las noticias policiales de las que somos testigos referenciales gracias a la actuación de los medios de comunicación, el crimen viene siendo fuente inagotable de indignación, desprecio, admiración, temor, y todo un cúmulo de sensaciones que hacen que la vida diaria, puesta como plato de fondo, necesite de una dosis de novela negra.

En ese intervalo de pasiones, podemos encontrar aquellas que la literatura ha adoptado para generar historias criminales, historias que, si bien es cierto, resultan ser ficción por excelencia, nos ayudan a comprender la situación reinante en un escenario delictivo. Una de ellas es la famosa novela Crimen y Castigo, obra cumbre del reconocido escritor ruso Fedor Dostoievski.

En Crimen y Castigo se suscita un delito. El asesinato cometido por Raskolnikov, un estudiante de medicina de origen muy humilde, quien carga sobre sus hombros el peso de la miseria no solo de él, sino de su hermana y madre, su corta familia. Ello, sumado a unos conflictos que afloran desde lo más profundo de su ser, desencadena que asesine a una vieja prestamista, Aliona Ivanovna, y a su hermana, Lizaveta, quienes hacían de la usura su modo de vida, para conseguir dinero y obtener satisfacción de sus necesidades materiales e inmateriales.

Dejando de lado la enorme riqueza en materia criminológica (psicológica) que la novela in comento nos ofrece, pretendemos aprovechar la gran cantidad de indicios y evidencias 
contenidos en ella para que, a través de la ciencia de la criminalística', podamos jugar un poco a ser detectives y lleguemos a individualizar al presunto responsable. De esta manera, determinaremos todas las circunstancias que han confluido a la hora de la comisión del delito.

\section{La escena del crimen ${ }^{2}$}

El asesinato de Aliona Ivanovna ocurrió en un lugar cerrado, un edificio de departamentos de varios pisos que tenía dos accesos; uno principal y uno accesorio a la derecha. Por este último acceso, se podía llegar al departamento de la víctima, situado en el cuarto piso, mediante una escalera de forma zigzagueante.

"Aquella casa se componia de pisos reducidos, y sus inquilinos eran toda suerte de gentes industriosas: sastres, cerrajeros, cocineros, varios alemanes, señoritas que vivian de lo suyo, modestos empleados. Los que entraban y los que salian encontrábanse en las dos puertas y en los dos patios de la casa. Habia alli tres o cuatro porteros". 3

En el mismo departamento, haciendo un análísis de lo narrado por Dostoievski, se encontraba un hall o sala de espera, una sala con varias ventanas, una cocina y una habitación, en donde descansaba la propietaria. Tomando como referencia a la puerta, que tenia la peculiaridad de abrirse para afuera, tenemos que el hall se ubicaba posterior a la puerta $y$ luego venia la sala, mas al fondo se ubicaba el dormitorio. A la izquierda de la sala y del hall se ubicaba la cocina,

En la sala, a una distancia prudencial de la ventana, y casi en el centro, se encontraba el cadáver de Aliona Ivanovna, recostado boca arriba con una pitillera de plata falsa en la mano, la misma que Raskolnikov fabricó para engañar a la vieja. Un poco más alejado, se encuentra el cadáver de Lizaveta Ivanovna en similar posición que el de Alicia. Ambos cadáveres están

La criminalística es definida como la ciencia que integra el conjunto de conocimientos técnico científicos aplicables a la investigación del delito, a fin de establecer, mediante estudios y análisis de los indicios y/o evidencias, los medios probatorios, forma y circunstancias de su perpetración, as como la identificación del autor (es) implicados. En "Guía de Procedimientos Criminalisticas de la PNP. Resolución. Directoral No 406-2005-DIRGEN/EMG. Pág. 10. Por su parte, una definición más contemporánea podría ser aquella que la define como la ciencia mediante la cual se procede al examen de indicios o evidencias de diverso origen y naturalezà, por párte de expertos forenses, con el objeto de plasmar la información obtenida en un pronunciamiento pericial que sirva de ilustración para un proceso judicial, administrativo o de indole particular. En RODRIGUEZ REGALADO, Pablo Alfonso. Aporte de la Ciencia criminalistica a la Seguridad Ciudadina, Arequipa: UNSA, 2004, pág. 64.

- La escena del crimen es definida como "aquel espacio, en el que se ha llevado la comisión de un acto calificado como delito, el mismo que puede o no dejar como resultado evidencias físicas, las que a su vez pueden o no estar focalizadas en ese mismo lugar". En: RODRIGUEZ REGALADO, Pablo Alfonso, "Carpetá de Trabajo del Maestrista Asignatura: Criminalística I", Arequipa: Escuela de Postgrado de la UCSM, 2009, pág. 105.

' DOSTOIEVSKI, Fedor Crimen y Gastigo. Lima: Editorial Mercurio, 1995. Pág. 8. 
rodeados de charcos de sangre. Además, se encuentran otros implementos de sala acordes a la época.

En el dormitorio podemos encontrar una cama enorme, una mesa de noche con unas llaves encima, un arca notable de capa combada totalmente abierta y vacía, y un trapo rojo al costado, en el piso. En la cocina, encontramos un lavatorio y encima de éste un jabón usado, una pieza blanca con manchas de sangre, un trapo con el que Raskolnivov se limpió las botas. Además, encontramos un paquete que había traído Lizaveta en sus manos, cuyo contenido no está detallado por el autor, No podemos obviar la importancia de la puerta, pues cuando dos personas intentaban ingresar luego de cometido el hecho delictivo, Raskolnikov manoseaba constantemente el cerrojo, lo que puede ser importante a efectos de una investigación. Habiendo determinado ya la escena del crimen en la obra de Dostoievski ${ }^{4}$, corresponde ahora adecuarla a los conocimientos y reglas que la ciencia de la criminalística nos ofrece.

\section{Búsqueda y ubicación de indicios y evidencias}

Sucedido el crimen, lo primero que debería realizar un perito en criminalística es buscar y ubicar los indicios ${ }^{5}$ y evidencias ${ }^{6}$ que se hallen en la escena del mismo, ello con el objeto de obtener medios probatorios, averiguar sobre la forma y circunstancias de su perpetración, así como la individualización del autor.

Para ello, la doctrina nos ofrece varios métodos. El más adecuado a nuestro entender en el crimen de Raskolnikov es el método de cuadros. Este consiste en dividir dos o más cuadrantes con tiza o crayón para realizar el registro del lugar metódicamente cuadro por cuadro, asignando un número y/o letra a cada uno de los cuadros y responsabilizando a un miembro del equipo la búsqueda en cuadros determinados. Este método es el que debe aplicarse a lugares cerrados, como el escenario que nos ocupa. Lo ideal sería que se distribuya la sala y cada uno de los ambientes y se encargue uno de ellos a un perito. Aplicando el referido método, podemos enumerar los elementos encontrados en la escena que podrían servir como indicios o evidencias:

- La escena del crimen aquí determinada es producto de lo narrado en el capítulo VTJ de la obra. Claro que nos hemos tomado la libertad de darle una ubicación, utilizando únicamente los elementos narrados en dicho capitulo.

5 Los indicios son las huellas, señales, signos o vestigios materiales de la actividad delictuosa, que mediante un análisis mental y/o instrumental nos pueden conducir al conocimiento de la verdad del hecho. Es una pista a seguir. Es subjetivo. En "Guía de Procedimientos Criminalísticas de la PNP". Resolución Directoral No 406-2005-DIRGEN/EMG. Pảg. 17

- Las evidencias son todo aquello observable, determinable y perceptible por los sentidos, de manera que no se puede dudar racionalmente de ello. Son objetivas y fácticas. ID. 
a) Los cadáveres

b) Las huellas de pisada de Raskolnikov

c) Las manchas de sangre

d) Las huellas digitales encontradas en la pitillera falsa de plata, en las llaves situadas encima de la mesa de noche, en el acta notable de capa combada, en el paquete que trajo Lizaveta, en el cańo del grifo de la cocina y en el cerrojo de la puerta.

e) El trapo rojo al costado del arca notable

f) La pieza blanca con que se limpió la sangre

g) El trapo con el que Raskolnikov se limpió las botas

\section{Perennización de la escena del crimen}

Identificados los elementos que pueden constituir indicios o evidencias, se debe proceder a perennizar la escena del crimen o registrar documentadamente los objetos en la posición y distancia en que se encuentran respecto al elemento central del hecho, en este caso el cadáver. Se toma, así, como punto de referencia elementos fijos, como paredes, puertas, ventanas, columnas y obras de arquitectura. Es necesario hacer la salvedad de que no se debe utilizar como referencia muebles y evidencias susceptibles de ser movidas o destruidas por persona o agentes atmosféricos, como lluvia, granizo, etc. Además, hay que tener siempre presente que se hace en forma paralela al ingreso a la escena del crimen. Previa enumeración, con una cámara fotográfica se podría realizar la referida labor. Si no hubiera una cámara, lo adecuado sería realizar planos de ubicación de los objetos o planimetría para tener la ubicación exacta de los elementos con referencia a puntos fijos.

\section{Recojo de indicios e evidencias}

Luego, se debe proceder al recojo de indicios y evidencias encontrados en la escena del crimen, debidamente enumerados. En los hallados en la casa de Aliona Ivanovna, el siguiente cuadro grafica el procedimiento adecuado para su recojo:

\begin{tabular}{l|l} 
Los cadáveres & $\begin{array}{l}\text { Labor encomendada a biólogos forenses, quienes, autorizados por el fiscal } \\
\text { y luego de haber perennizado correctamente la escena, proceden a levantar } \\
\text { los cadáveres y llevarlos al Instituto de Medicina Legal. }\end{array}$
\end{tabular}

"Guía de Procedimientos Criminalisricas de la PNP", Resolución Directoral No 406-2005-DIRGEN/EMG. Pág. 27 


\begin{tabular}{|c|c|}
\hline $\begin{array}{l}\text { Las huellas de pisada } \\
\text { de Raskolnikov }\end{array}$ & $\begin{array}{l}\text { Siendo posible la ubicación de huellas de pisada en las superficies de los } \\
\text { ambientes antes mencionados, lo adecuado sería descubrir de primera } \\
\text { intención las mismas por medio de la luz oblicua de una linterna aplicada en } \\
\text { la penumbra. Luego, se debe fotografiarla con el mismo tipo de iluminación. } \\
\text { Se puede levantar con adhesivo plástico, de ramaño apropiado y a falta de } \\
\text { este se podrá utilizar papel fotográfico previamente remojado para que se } \\
\text { ablande la emulsión que es la que recogerá la huella. }\end{array}$ \\
\hline $\begin{array}{l}\text { Las manchas de } \\
\text { sangre }\end{array}$ & $\begin{array}{l}\text { Antes de recoger muestras de manchas de sangre, se deben fotografiar éstas } \\
\text { en su totalidad, tratando de que en la fotografía aparezca el cadáver u otras } \\
\text { evidencias próximas. Siendo abundante la cantidad de sangre encontrada, } \\
\text { se debe recoger por medio de una jeringa hipodérmica y se deposita en } \\
\text { un rubo de ensayo que se tapará con un material permeable como gasa } \\
\text { o algodón. La posición de las manchas es muy importante, porque nos } \\
\text { puede ayudar a determinar cómo se prodajo el hecho, el mecanismo de } \\
\text { caída o desfallecimiento de la víctima, y la posición en que ésta quedó. Por } \\
\text { eso, es necesario observar la parte del cuerpo donde se hallan las heridas y } \\
\text { determinar de primera intención si la sangre de la mancha que examinamos } \\
\text { se produjo estando aun la persona con vida y de pie, o si esa mancha es } \\
\text { el resultado de la hemorragia consecuente de la caída. Se debe calcular } \\
\text { la cantidad de sangre que se encuentra en la escena y relacionarla con las } \\
\text { heridas de la víctima para determinar, por deducción, si puede tratarse de } \\
\text { sangre del heridor o si se ha lavado algunas manchas, etc. }{ }^{2}\end{array}$ \\
\hline $\begin{array}{l}\text { Las huellas digitales } \\
\text { encontradas en la } \\
\text { pitillera falsa de } \\
\text { plata, las Ilaves } \\
\text { situadas encima de } \\
\text { la mesa de noche, el } \\
\text { acta notable de capa } \\
\text { combada, el paquete } \\
\text { que trajo Lizaveta, el } \\
\text { caño del grifo de la } \\
\text { cocina, y el cerrojo } \\
\text { de la puerta. }\end{array}$ & $\begin{array}{l}\text { Siendo los objetos que podrían contener las huellas del asesino instrumentos } \\
\text { móviles (con excepción del cerrojo de la puerta y el caño de grifo de la } \\
\text { cocina), lo mejor será que, luego de perennizada la escena con la cámara } \\
\text { fotográfica, se proceda a recoger dichos instrumentos con guantes del } \\
\text { sector del objeto que no pueda contener huellas, para no borrar las mismas. } \\
\text { Posteriormente, embalarlos (asegurándolos a una madera y atándolos con } \\
\text { una cuerda nylon gruesa) y enumerarlos, evitando todo contacto con la } \\
\text { zona que contenga las posibles huellas. } \\
\text { En cuanto al caño del grifo de la cocina y el cerrojo de la puerta, el } \\
\text { descubrimientó de las huellas digitales puede ser efectuado sometiendo la } \\
\text { huella a la luz oblicua. Pero lo más práctico es emplear reactivos especiales } \\
\text { por toda el área sospechosa, merced a los cuales aparecerán las huellas } \\
\text { digitales latentes sin necesidad de buscarlas una por una con luz oblicua. }{ }^{3}\end{array}$ \\
\hline
\end{tabular}

Manual de Criminalistica PIP. Primera Parte. Lima,1966. Página 38.

2 Ibíd., pág. 41.

3 Ibid., pág. 40. 
El trapo rojo al costado del arca notable, la pieza blanca con que se limpio la sangre; y el trapo con el que Raskolnikoy se limpió las botas.
Se debe dejar secar la sangre contenida en dicha prenda. Se debe embalar adecuadamente en papel. Y luego se envía al laboratorio.

Luego del recojo de indicios y evidencias, se procede al embalaje adecuado de los mismos y se transporta al lugar determinado para su examen.

\section{Cadena de custodia}

La cadena de custodia es un procedimiento recomendado para asegurar la integridad de la muestra. Se inicia, no cuando el indicio y/o evidencia es recogido por el perito de criminalística, sino desde el momento que se verifica la comisión del hecho delicruoso. Necesariamente, estará a cargo del personal interviniente en una primera instancia hasta que llegue al laboratorio para su estudio, manteniéndose cuando las evidencias tienen que ser puestas a disposición de la autoridad judicial competente y requieren la adopción de ciertas medidas de seguridad para que no se extravien. ${ }^{8}$ Es importante el resguardo de todos los indicios y evidencias adecuadamente, de manera que la criminalística cumpla con sus objetivos.

\section{Criminalistica de laboratorio}

Una vez llevados los indicios al laboratorio, corresponde hacer el análisis de los mismos, utilizando todos los recursos que la ciencia pone a nuestro alcance. En el caso que nos ocupa, tenemos lo siguiente:

\section{a. Los cadáveres}

Los cadáveres deben ser analizados por médicos legistas, en el Instituto Médico Legal o la morgue correspondiente. Siendo la muerte de Aliona Ivanovna producía por un hacha, se debe tener en cuenta lo siguiente

- Un cadáver asesinado mediante un hacha presenta con frecuencia signos de su

" "Guía de Procedimientos Criminalísticas de la PNP". Resolución Directoral No 406-2005-DIRGEN/EMG. Pág. 34 
utilización por haber entrado en contacto con el cuerpo de la víctima, tales como sangre, pelos, piel, grasas, restos de tejidos, etc.

- Generalmente en estos casos existe resistencia por parte de la víctima. Por esta razón, se producen heridas en las manos, brazos, antebrazos, pecho, piernas, rodillas, etc. Se trata de las llamadas heridas de defensa, las cuales indican la reacción instintiva de la vícrima.

- Es importante estudiar también la expresión del rostro de la víctima al morir, la misma que puede determinar la sorpresa a la hora de cometer la agresión,

- Sobre las prendas, creemos adecuado que se envíen las mismas al laboratorio de criminalística para la identificación de posibles huellas de contacto con el asesino, así como para el estudio de las manchas de sangre.

\section{b. Las huellas de pisada de Raskolnikov}

Teniendo perennizadas las huellas del asesino mediante mecanismos adecuados, se debe cotejar la huella perennizada con los zapatos que utilicen todos los posibles sospechosos del ilícito. De esa forma, se tendrá una evidencia respecto de su presencia en la escena del crimen a la hora del delito.

\section{c. Las manchas de sangre}

En la escena del crimen se han encontrado manchas por proyección (gotas y salpicaduras), manchas por escurrimiento (charcos, regueros), manchas por limpiamiento (en el trapo rojo al costado del arca notable, la pieza blanca con que se limpio la sangre y el trapo con el que Raskolnikov se limpió las botas) y, posiblemente, manchas de contacto y de impregnación con los mismos elementos donde hay manchas de limpiamiento. ${ }^{9}$ Las machas de proyección nos ayudaran a determinar la dirección del ataque, así como la posición del agresor y de la vicrima a la hora del asesinato. Teniendo en cuanta la superficie del piso, y la forma de las gotas encontradas, podremos determinarlo. Creemos que en el piso se han encontrado gotas redondas con dentellones, y gotas alargadas con proyecciones también largas en la parte delantera, estas proyecciones siempre se ubican en sentido contrario a la dirección de la agresión. ${ }^{10}$ De encontrarse gotas en la pared, las mismas siempre serán alargadas, y las proyecciones largas también van en sentido contrario a la dirección de la agresión. ${ }^{11}$

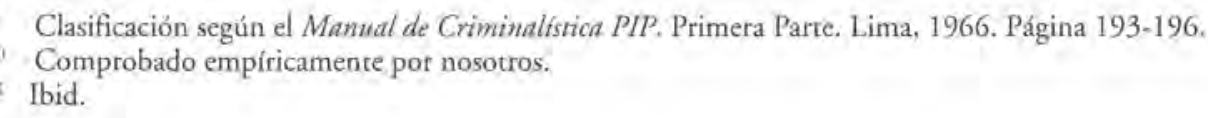


Las manchas de escurrimiento, de limpiamiento, de contacto y de impregnación, determinaran que efectivamente el asesino tenía intención de borrar todas las posibles huellas de su delito. Trasladando el crimen de Raskolnikov a la actualidad, hoy se podría practicar un examen de $A D N$ en la sangre encontrada, para determinar si la misma corresponde a la víctima o al agresor. De manera que, encontrado el código genético, podamos homologarlo con el de los posibles sospechosos, y llegar al responsable.

\section{d. Las huellas digitales}

El indicio más importante que nos puede llevar a identificar a Raskolnikov es el de las huellas digitales. Por el Principio de intercambio de Locard, cada vez que dos objetos entran en contacto debe haber siempre una transferencia o intercambio de elementos entre ambos ${ }^{12}$. En este caso entre el sujeto y la escena. Raskolnikov cometió errores garrafales en la comisión tan cautelosa de su crimen: cogió unas llaves, dejadas encima de la mesa de noche de Aliona, cogió la pitillera de plata falsa luego de muerta Aliona, el arca notable de capa combada, el paquete que trajo Lizaveta, el caño del grifo de la cocina, y el cerrojo de la puerta. Además, dejó elementos o huellas de sus manos en la escena del crimen. Si utilizamos el método de las sustancias fluorescentes, incluso en la vestimenta de los cadáveres, podemos llegar a fotografiar las huellas digitales encontradas y homologarlas con las de todos los sospechosos, determinando cuál de ellos es el que estuvo en la escena del crimen a la hora de cometer el ilícito.

\section{Epílogo: no hay crimen perfecto}

La primera vez que entramos en contàcto con Crimen y Castigo creemos que es un manual para cometer un asesinato perfecto. La forma de su comisión y el desenlace de la novela refirman nuestra opinión en ese sentido. La ingenuidad nos absuelve de equivocarnos y la criminalística justifica su existencia en esa absolución. Nacida en el seno del delito, se constituye en la herramienta fundamental para determinar las circunstancias de un crimen y los responsables del mismo, partiendo del análisis de indicio y evidencias. $Y$ el transcurrir de los años hace que su transcendencia aflore y apasione cada vez más a las masas.

Para la criminalística no hay crimen perfecto. Si Dostoievski la hubiese conocido, tal vez le hubiese dado orro desenlace a Crimen y Castigo. Existía la sospecha de los agentes de la pólicía. Bastaba con practicarle exámenes en sus huellas y homologarlas con las extraídas en

\footnotetext{
RODRIGUEZ REGALADO, Pablo. Carpeta de Trabajo del Maestrista Asignatura: Criminalística I", Arequipa: Escuela
} de Postgrado de la UCSM, 2009, pág. 45. 
la escena del crimen para llegar a puerto seguro. Tal vez, la criminalística nos hubiese quitado la enorme riqueza criminológica de Crimen y Castigo. Pero mientras sigan existiendo delitos, estará, cual herramienta lista a ser utilizada en el mundo de las incertidumbres, para brindar su mano a la investigación policial. Porque, como dice Dostoievki:

"Todos los delincuentes, sean cual fueren, experimentan, en el momento de cometer su crimen, como un desfallecimiento de la voluntad de juicio, cuyo puesto viene a suplantar un atolondramiento fenomenal y pueril, precisamente en el instante en que más necesarias les serian la razón y la prudencia." 13

He ahí dónde empezar.

13 DOSTOIEVSKI, Fedor. Crimen y Castigo. Lima: Editorial Mercurio, 1995. Pág. 34. 


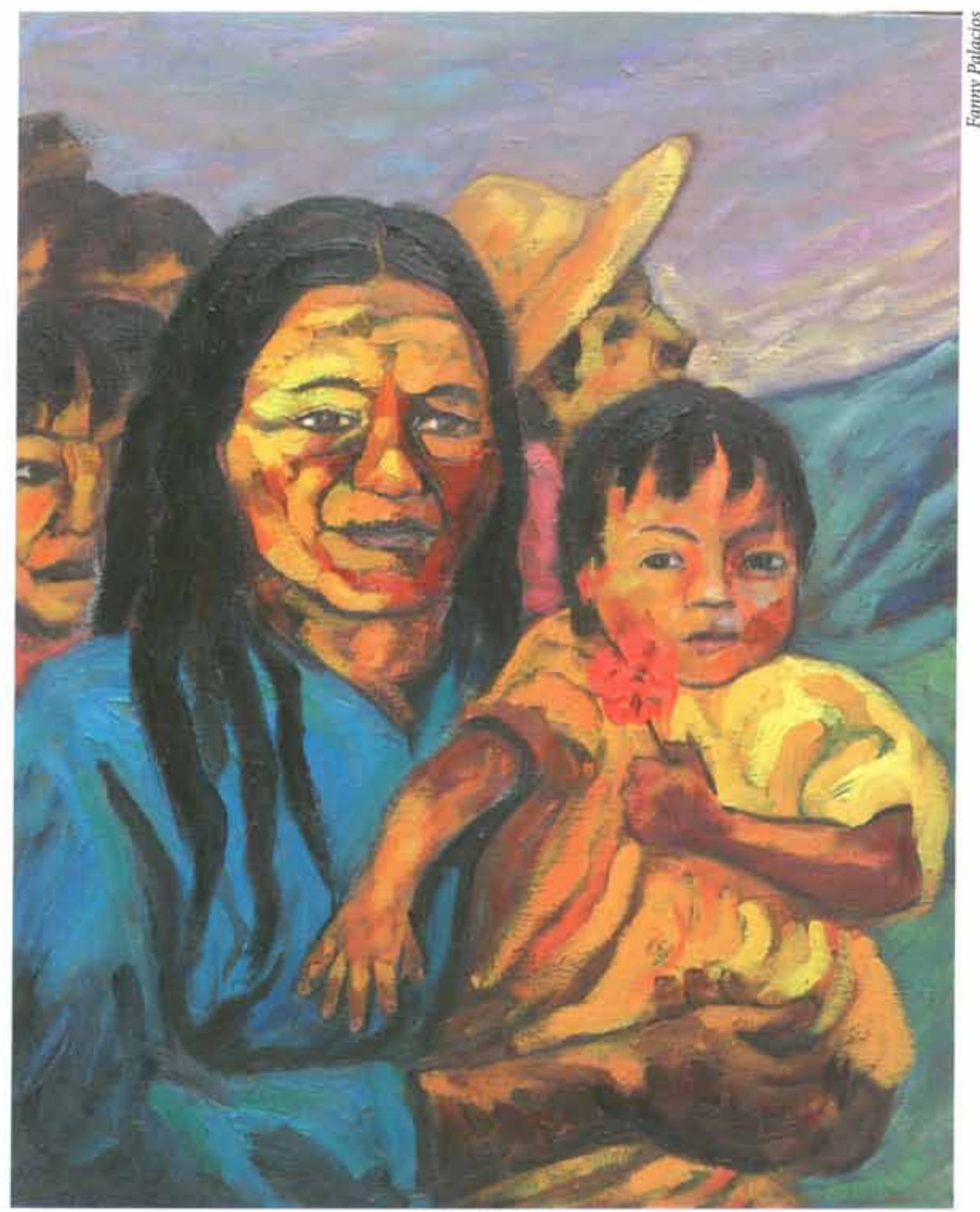

"Maternidad II" 